\title{
The Impact of Human Resource Management on Small and Medium Enterprise Success in Hong Kong
}

\author{
Fanny Yuk Fun Young* \\ Hong Kong Shue Yan University, Hong Kong
}

\begin{abstract}
The aim of this project is to determine the association between different human resource management (HRM) practices and business success in small and medium enterprises in Hong Kong. The 1300 entrepreneurs were randomly drawn from the membership list of the Hong Kong Small and Medium Enterprise (SME) Association and the number of responded questionnaires was 394. Based on the responses, the extent of each HRM practice was correlated with the degree of business success. The correlation coefficient, Spearman $r$ were ranged from 0.64 to 0.83 . In conclusion, HRM practices were significantly correlated with business success in the SMEs in Hong Kong.
\end{abstract}

Keywords: Human resource management, business success, small and medium enterprises, job analysis, human resource planning, training, performance appraisal.

\section{INTRODUCTION}

The growing speed of technological change has meant firstly, that businesses have had to learn to make decisions faster and, secondly, that the cost of making judgment errors has also increased. Technological practice is a recognizable commodity, and its effect on the success of a business is reasonably easily determined. Management of the human 'process' however, is less visible, but errors can make for costly reconstruction, if not total loss of the business.

In his textbook on Management, Dessler [1] stated “... it is possible to do everything else right as a manager - lay brilliant plans, draw clear organization charts, set up modern assembly lines, and use sophisticated accounting controls but still fail as a manager by hiring the wrong people or by not motivating subordinates." It seems that good human resource management (HRM) skills are needed in order to ensure business success.

However, little is known about the direct relationship between these human elements and the success of firms, and this gap presented the researcher with an opportunity to explore and to gain a little more understanding of the relationship should it, in fact, exist in reality.

Upon the British colonial take-over in 1842, Hong Kong transformed into an entrepôt between China and the rest of the world. The large influx of refugees from mainland China in 1950s gave impetus for Hong Kong's industrialization. In 1960s Hong Kong became East Asia's major economic centre. Since the 1980s, it also has developed into a major trading and financial centre for the world-as-a-whole [2]. At the same time, Hong Kong has evolved from a manufacturing economy into a service economy. The political condition of Hong Kong was changed with the handover of Hong Kong

*Address correspondence to this author at the Hong Kong Shue Yan University, 10 Wai Tsui Cresent, Braemer Hill, North Point, Hong Kong; Tel: (852) 2570 7110; E-mail: fyoung@pacific.net.hk back to China in 1997. Hong Kong was hard hit by the financial crisis in the same year and suffered from a sluggish economy accompanied by soaring unemployment. Moreover, the accession of China to World Trade Organization (WTO) membership undermined the role played by Hong Kong as a gateway to world commerce [3]. On the other hand, Hong Kong has had the opportunity to work more closely with the Mainland China, with the CEPA (The Mainland and Hong Kong Closer Economic Partnership Arrangement) signed on 29 June 2003. Under terms of this agreement, Hong Kong enjoyed trade liberalization measures with the Mainland China [4]. With such a dramatic change in political and economic situation, it is imperative to the development of a reflective picture of the Island State, and of course highly interesting to study the enterprises in Hong Kong.

It is important to study the Small and Medium Enterprise (SME) in Hong Kong as SMEs accounted for over 98\% of the total businesses in Hong Kong (Government of HKSAR, 2006). As the enterprises of Hong Kong emerge out of its unique environment, the experience of Hong Kong is very helpful to developing economies. Business research studies of Hong Kong's style of enterprises are few [5].

Hong Kong SMEs need to have a better understanding of the impact their human resource decisions are having, and researchers need to have a clearer picture of the relationship and its HRM based theoretical foundation.

Increasing competition from outside Hong Kong is putting pressure on Hong Kong based businesses to develop a greater control over all factors of production. These factors include the human contribution, and this element is vital to business success. Moreover, the last comprehensive study on the HRM practices in Hong Kong was seventeen years ago by Goh and Cheung [6], long before the Handover of Hong Kong. It is timely to have another study as it may reveal meaningful information. The current study sought to gain 
current information about the practices of HRM and further, their impact on business success, to assist in advancing the understanding to benefit SME practitioners and researchers.

The aim of this study was to determine the relationship between HRM practices with SME success in Hong Kong. Additionally, to identify the importance of various HRM practices, namely job analysis, human resource planning, training and performance appraisal, with the SME success in Hong Kong.

\section{HYPOTHESES}

Job analysis; human resource planning; training and performance appraisal were chosen to be the HRM practices to be investigated.

$\mathrm{H}_{1}$ : The extent of job analysis is related significantly to success.

$\mathrm{H}_{2}$ : The extent of human resource planning is related significantly to success.

$\mathrm{H}_{3}$ : The extent of training is related significantly to success.

$\mathrm{H}_{4}$ : The extent of performance appraisal is related significantly to success.

\section{METHOD}

The study population is made up of SME's in Hong Kong. SMEs in this study are defined as manufacturing enterprises (includes Mining and Quarrying, Electricity and Gas and Construction) with fewer than 100 employees and non-manufacturing enterprises (includes Import/Export Trades, Wholesale and Retail Trades, Restaurants and Hotels, Financing, Insurance, Real Estate and Business Service,
Community, Social and Personal Services, Transport, Storage \& Communications) with fewer than 50 employees.

The project was a quantitative study on SMEs using a field survey. The sample size for the respondents needed was determined to be a minimum of 384 since this sample needed to represent the 284000 SMEs in Hong Kong, it needed to provide statistical significant comparison [7] and correlations to be performed. This agreed with the sample size of 400 of a similar study [6]. The response rate of mail surveys was expected to be $30 \%$ [8], therefore 1300 questionnaires were sent out in order the number of responded questionnaires would reach this level.

In the administration, the methods modified from similar studies [6] were employed. The 1300 SMEs were randomly drawn from the membership list of the Hong Kong Small and Medium Enterprise Association. This excluded the soletraders from the study because they are not members of that association. An invitation letter together with an anonymous questionnaire was mailed to each potential participant. Only those who voluntarily agreed to participate were required to return the questionnaire anonymously in a prepaid envelope with no participant identifying marks, addressed to a post office box.

The questionnaire (appendix) consisted of five sections, the first four sections were related to each HRM practice to be investigated. Based on previous studies on HRM practices [6], the questionnaire was designed so that the summation of the responses in each section would be the indication of the extent of that HRM practice in that SME. The last section of the questionnaires was to measure business success. Similarly, the questionnaires were designed so that the success index, defined as the summation of the responses in that section, would be the indication of the degree of business suc-

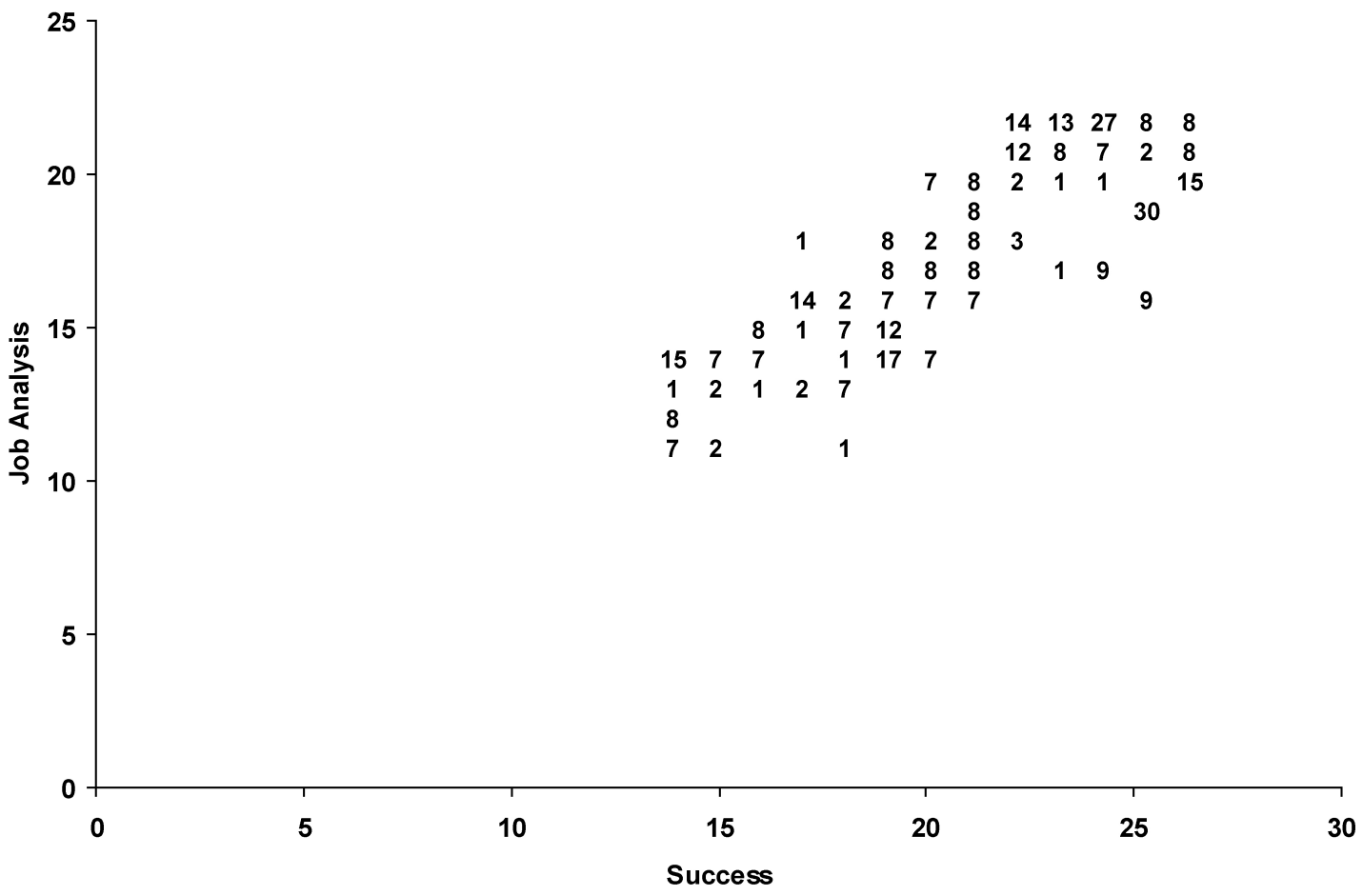

Fig. (1). Plotting of the extent of job analysis (summation Q1+Q2 responses) of one SME against success index (summation Q.14-Q.20 responses). The position of the numbers represents the position of the plot while their value denotes the number of response in that plot. 
cess. The extent of each HRM practice was then related with the success index using correlation analysis.

\section{RESULTS}

Among the 1300 questionnaires sent 394 SMEs responded and returned the questionnaires. The response rate was $30.3 \%$ which was close to the initial expectations.

\section{Job Analysis and Success}

To test for $\mathrm{H}_{1}$ : the extent of job analysis was related significantly to success, the summations of the responses of item 1 and 2 of different companies (Q.1+Q.2) were correlated with their success indices (summation Q.14-Q.20) using correlation analysis. The Spearman $r$ was 0.75 . Statistic test showed that $r$ was significantly different than zero $(\mathrm{P}<$ 0.0001 ). A plotting of the extent of job analysis of different companies (Q.1+Q.2) against their success indices was shown on Fig. (1). Some linear relationship between the extent of job analysis and the success index could be found.

\section{Human Resource Planning and Success}

To test for $\mathrm{H}_{2}$ : the extent of human resource planning was related significantly to success, the summations of the responses of item 3 and 4 of different companies (Q.3+Q.4) were correlated with their success indices (summation Q.14Q.20) using correlation analysis. The Spearman $r$ was 0.64. Statistic test showed that $r$ was significantly different than zero $(\mathrm{P}<0.0001)$, considered extremely significant. A plotting of the extent of human resource planning of different companies $(\mathrm{Q} 3+\mathrm{Q} 4)$ against their success indices (summation Q.14-Q.20) was shown on Fig. (2). Some linear relationship between the extent of human resource planning and the success index could be found.

\section{Training and Success}

To test for $\mathrm{H}_{3}$ : the extent of training was related significantly to success, the summations of the responses of item 5 to 9 of different companies (summation Q.5-Q.9) were correlated with their success indices (summation Q.14-Q.20) using correlation analysis. The Spearman $r$ was 0.69 . Statistic test showed that $r$ was significantly different than zero $(\mathrm{P}<$ 0.0001). A plotting of the extent of training of different companies (summation Q.5-Q.9) against their success indices (summation Q.14-Q.20) was shown on Fig. (3). Some linear relationship between the extent of training and the success index could be found.

\section{Performance Appraisal and Success}

To test for $\mathrm{H}_{4}$ : the extent of performance appraisal was related significantly to success, the summations of the responses of item 10 to 13 of different companies (summation Q.10-Q.13) were correlated with their success indices (summation Q.14-Q.20) using correlation analysis. The Spearman $\mathrm{r}$ was 0.83 . Statistic test showed that $\mathrm{r}$ was significantly different than zero $(\mathrm{P}<0.0001)$. A plotting of the extent of performance appraisal of different companies (summation Q.10Q.13) against their success indices (summation Q.14-Q.20) was shown on Fig. (4). Some linear relationship between the extent of performance appraisal and the success index could be found.

\section{DISCUSSION}

\section{Job Analysis and Company Success}

Using correlation analysis, the summations of the responses of items 1 and 2 of different companies were correlated with their success indices. The Spearman $r$ was 0.75 .

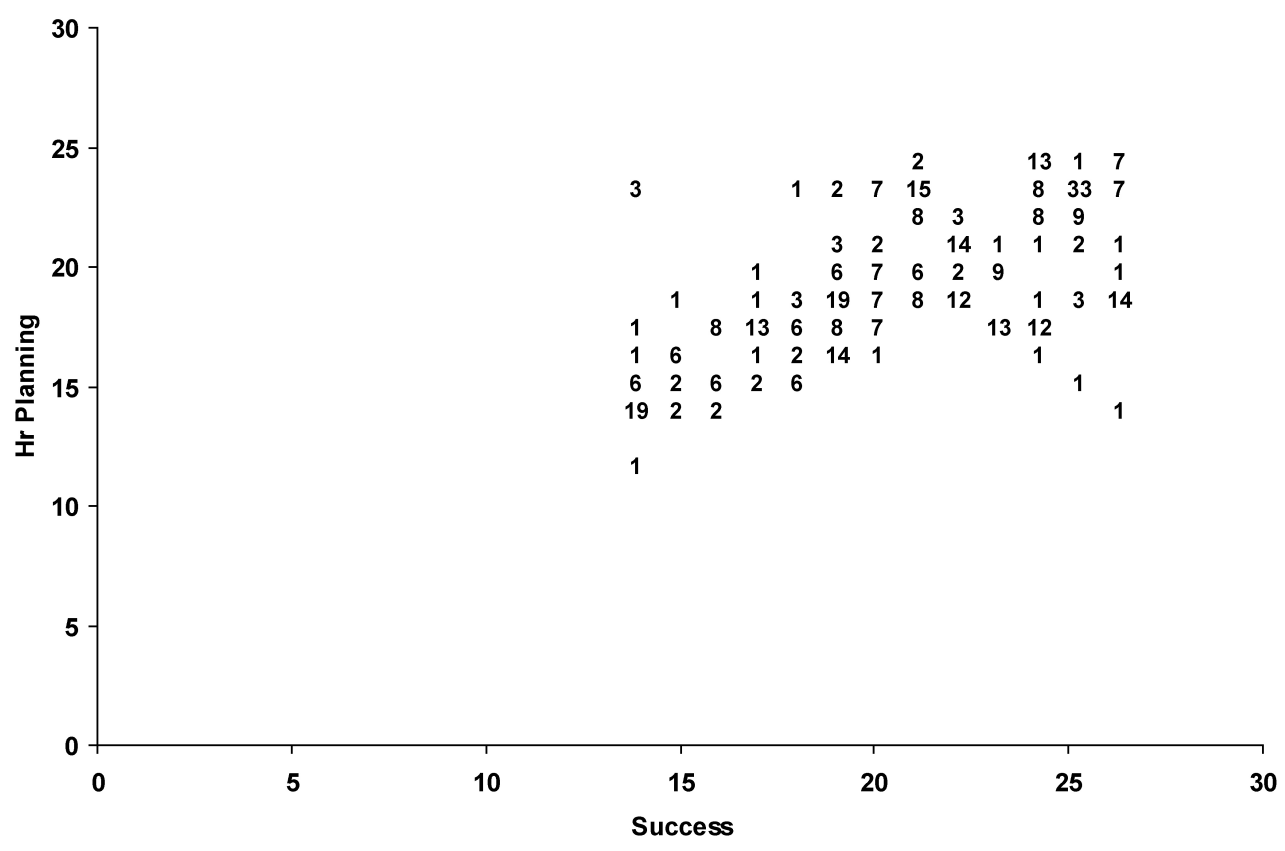

Fig. (2). Plotting of the extent of human resource planning (summation Q3+Q4 responses) of different SMEs against success index (summation Q.14-Q.20 responses). The position of the number represents the position of the plot while its value denotes the number of response in that plot. The position of the numbers represents the position of the plot while their value denotes the number of response in that plot. 


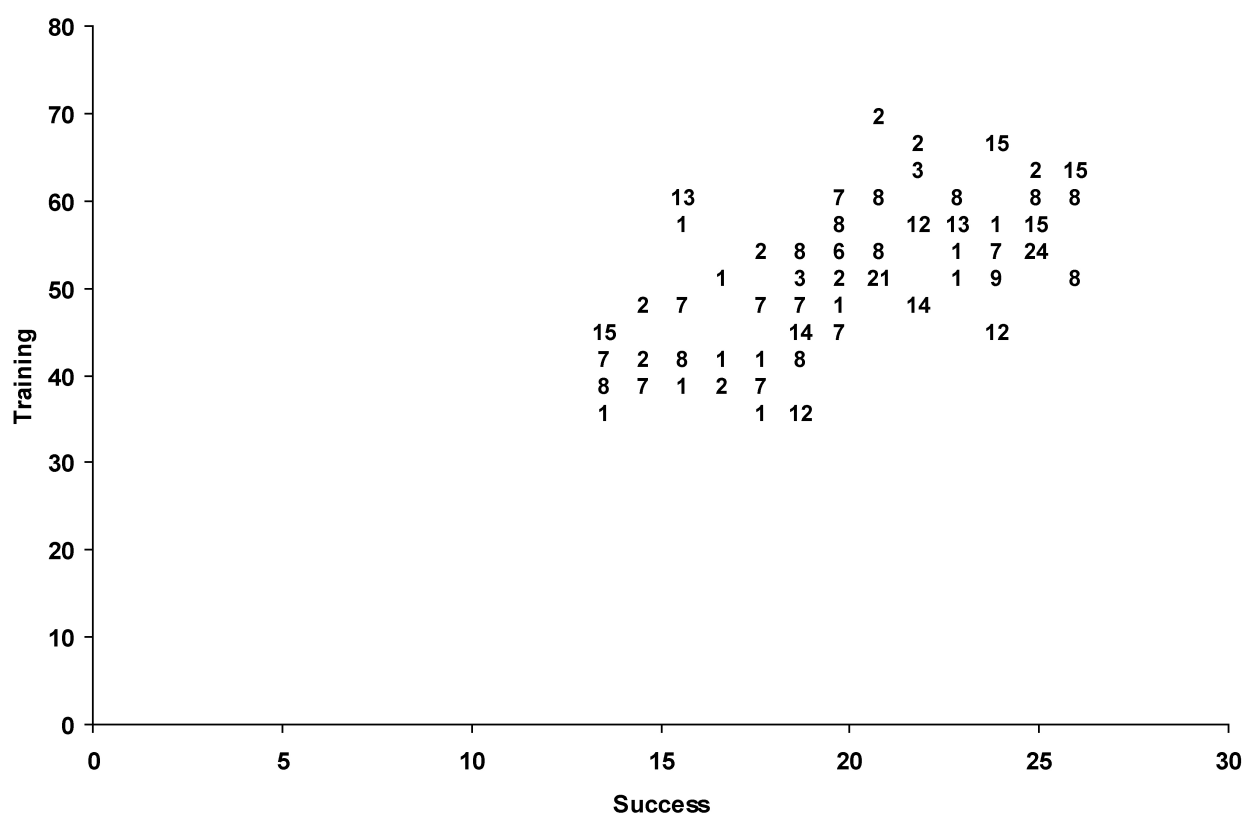

Fig. (3). Plotting of the extent of training (summation Q.5-Q.9 responses) of different SMEs against success index (summation Q.14-Q.20 responses). The position of the number represents the position of the plot while its value denotes the number of response in that plot.

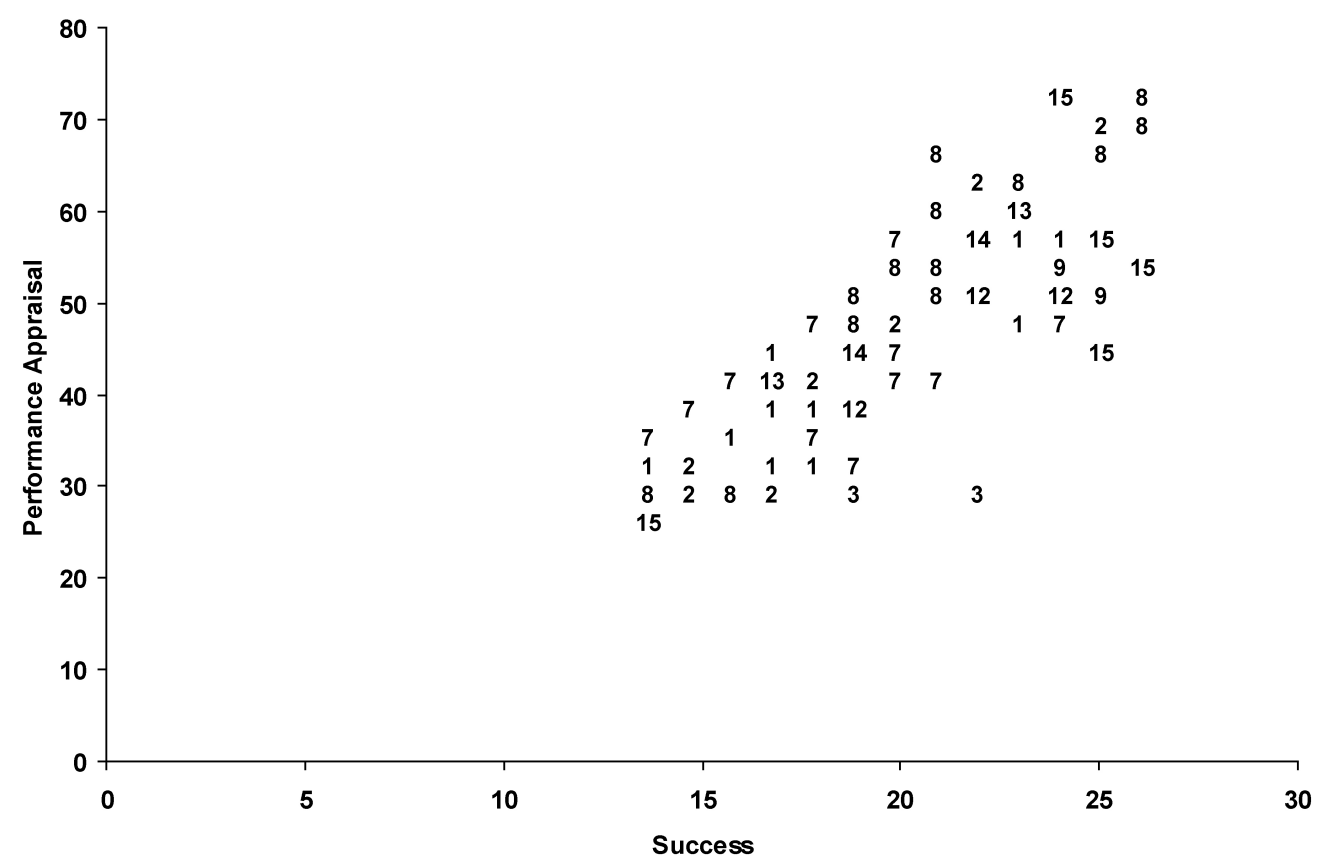

Fig. (4). Plotting of the extent of performance appraisal (summation Q.10-Q.13 responses) of different SMEs against success index (summation Q.14-Q.20 responses). The position of the number represents the position of the plot while its value denotes the number of response in that plot.

Spearman Rank Correlation was used because it does not assume Gaussian distribution of the responses this also applied to the other analyses of this study. The Spearman $r$ showed that there was an association between the summations of the responses of item 1 and 2 of different companies and the success indices. The summation of the responses of item 1 and 2 is an indicator of the extent of practice in job analysis in the company [6]. Furthermore, a plotting the extent of job analysis of different companies against their success indices showed some linear relationship between the extent of job analysis and the success index (Fig. 1). There- fore the extent of job analysis was related significantly to success, supporting $\mathrm{H}_{1}$.

\section{Human Resource Planning and Company Success}

Using correlation analysis, the summations of the responses of item 3 and 4 of different companies were correlated with their success indices. The Spearman Rank Correlation, Spearman $r$ was 0.64 . The Spearman $r$ showed that there was an association between the summations of the responses of items 3 and 4 of different companies and the suc- 
cess indices. The summation of the responses of items 3 and 4 is an indicator of the extent of practice in human resource planning in the company [6]. Furthermore, a plotting the extent of human resource planning of different companies against their success indices showed some linear relationship between the extent of human resource planning and the success index (Fig. 2). Therefore the extent of human resource planning was related significantly to success, supporting $\mathrm{H}_{2}$.

\section{Training and Company Success}

Using correlation analysis, the summations of the responses of item 5 to 9 of different companies were correlated with their success indices. The Spearman Rank Correlation, Spearman $r$ was 0.69. The Spearman $r$ showed that there was an association between the summations of the responses of item 5 to 9 of different companies and the success indices. The summation of the responses of items 5 to 9 is an indicator of the extent of practice in training in the company [6]. Furthermore, a plotting the extent of training of different companies against their success indices showed some linear relationship between the extent of training and the success index (Fig. 3). Therefore the extent of training was related significantly to success, supporting $\mathrm{H}_{3}$.

\section{Performance Appraisal and Company Success}

Using correlation analysis, the summations of the responses of items 10 to 13 of different companies were correlated with their success indices. The Spearman Rank Correlation, Spearman $r$ was 0.83 . The Spearman $r$ showed that there was an association between the summations of the responses of item 10 to 13 of different companies and the success indices. The summation of the responses of item 10 and 13 is an indicator of the extent of practice in performance appraisal in the company [6]. Furthermore, a plotting the extent of performance appraisal of different companies against their success indices showed some linear relationship between the extent of performance appraisal and the success index (Fig. 4). Therefore the extent of performance appraisal was related significantly to success, supporting $\mathrm{H}_{4}$.

In this study, all of the four HRM practices investigated were shown to have positive correlation with success. Among those, performance appraisal showed the highest correlation (Spearman $r=0.83$ ), followed by job analysis (Spearman $r=0.75$ ), training (Spearman $r=0.69$ ) and human resource planning (Spearman $r=0.64$ ).

It is possible that the motivation effect of performance appraisal to employees is more consistent than the other HRM practices. A variation of different training, job analysis and human planning methods might cause different effects and this might explain the lower correlation of these three HRM practices to success. Further studies are needed to identify which particular methods of HRM practices are more consistent and effective in bringing success. In addition, this study only showed the association, it did not prove the cause and effect relationship between HRM practices and business success. The latter, obviously, involves a multitude of factors and need longitudinal studies to vertify.

The relationship between performance appraisal and success can be appreciated if we understand performance appraisal provides information upon which managers can make promotion and salary decisions; an opportunity for managers and subordinates to review their work-related behaviours; an opportunity to review the person's career plans in light of his or her strengths and weaknesses and it helps managers to better manage and improve the firm's performance.

\section{CONCLUSIONS}

In conclusion, the results supported the hypotheses that the extents of HRM practice were related significantly to business success in the SMEs in Hong Kong. Among those, performance appraisal was more highly correlated with business success.

\section{APPENDIX: QUESTIONNAIRE (GOH AND CHEUNG, 1989)}

1) Do you agree your organization have written job descriptions for individual jobs?

$\begin{array}{lllllll}\text { Strongly disagree } & 1 & 2 & 3 & 4 & 5 & \text { Strongly agree }\end{array}$

2) Which of the following methods are used in your organisation for job analysis? Please tick the appropriate number alongside each method, and add any you use, but which are not listed, indicating the amount it is used.

$\begin{array}{lccccc} & \text { Don't } & \text { Never } & \text { Rare } & \text { Sometimes } & \\ & \text { know } & & & 4 & 5 \\ \text { 1. Observation } & 1 & 2 & 3 & 4 & 5 \\ \text { 2. Interview } & 1 & 2 & 3 & 4 & 5 \\ \text { 3. Participant Diary / Logs } & 1 & 2 & 3 & 5 \\ \text { 4. Questionnaire } & 1 & 2 & & 5\end{array}$

5. Others, please specify

3) Do you agree there should be a human resource plan for your organization? 
4) Which of the following methods are used in your organisation to forecast required staffing levels? Please tick the appropriate number alongside each method, and add any you use, but which are not listed, indicating the amount it is used.

1. Trend Analysis

Don't

Never

Rare

Sometimes

Always

2. Ratio Analysis

3. Computerized Forecasts

know

4. Managerial Judgment

1
1
1
1

2
2
2
2

3
3
3
3

5. Others, please specify

5) Do you agree there should be a Specialist Training Department in your organization?
Strongly disagree
2
3
4
5
Strongly agree

6) By what methods are training needs analysed in your organisation? Please tick the appropriate number alongside each method, and add any you use, but which are not listed, indicating the amount it is used.

\begin{tabular}{|c|c|c|c|c|c|}
\hline & Don't & Never & Rare & Sometimes & Always \\
\hline & know & & & & \\
\hline 1. Job Analysis & 1 & 2 & 3 & 4 & 5 \\
\hline 2. Performance appraisal & 1 & 2 & 3 & 4 & 5 \\
\hline 3. Review of problem areas & 1 & 2 & 3 & 4 & 5 \\
\hline 4. Interviews & 1 & 2 & 3 & 4 & 5 \\
\hline 5. Questionnaires & 1 & 2 & 3 & 4 & 5 \\
\hline 6. Not analysed & 1 & 2 & 3 & 4 & 5 \\
\hline
\end{tabular}

7) Do you agree your organization organize in-house training courses for employees?
Strongly disagree
1
2
3
4
5
Strongly agree

8) Which of the following training methods are used in your organization for different types of in-house training? Please tick the appropriate number alongside each method, and add any you use, but which are not listed, indicating the amount it is used.

\begin{tabular}{|c|c|c|c|c|c|}
\hline & Don't & Never & Rare & Sometimes & Always \\
\hline & know & & & & \\
\hline 1. Lecture/seminar & 1 & 2 & 3 & 4 & 5 \\
\hline 2. Small group discussion & 1 & 2 & 3 & 4 & 5 \\
\hline 3. Role playing & 1 & 2 & 3 & 4 & 5 \\
\hline 4. Game & 1 & 2 & 3 & 4 & 5 \\
\hline 5. Simulation exercise & 1 & 2 & 3 & 4 & 5 \\
\hline 6. Case study & 1 & 2 & 3 & 4 & 5 \\
\hline 7. Project & 1 & 2 & 3 & 4 & 5 \\
\hline 8. Coaching & 1 & 2 & 3 & 4 & 5 \\
\hline
\end{tabular}

9) What is the $\%$ of training expenditure to total staff payroll in your organisation? 
10) Do you agree your organization should have a system of performance appraisal?

Strongly disagree 2 3

4

11) How often are performance appraisals carried out in your organisation?

1. Never or rarely

2. Every 1 year

3. Every 2 years

4. Every 6 months

12) Which methods of appraisal are used in your organization? Please tick the appropriate number alongside each method, and add any you use, but which are not listed, indicating the amount it is used.

\begin{tabular}{|c|c|c|c|c|c|}
\hline & Don't & Never & Rare & Sometimes & Always \\
\hline & know & & & & \\
\hline 1) Graphic Rating Scale Method & 1 & 2 & 3 & 4 & 5 \\
\hline 2) Forced Distribution Method & 1 & 2 & 3 & 4 & 5 \\
\hline 3) Critical Incident Method & 1 & 2 & 3 & 4 & 5 \\
\hline 4) Management by Objective (MBO) & 1 & 2 & 3 & 4 & 5 \\
\hline 5) Computerized and Web-based Performance Appraisal & 1 & 2 & 3 & 4 & 5 \\
\hline 6) Self- rating & 1 & 2 & 3 & 4 & 5 \\
\hline 7) $360^{\circ}$ appraisal & 1 & 2 & 3 & 4 & 5 \\
\hline 8) Others, please specify & 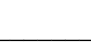 & & & & \\
\hline
\end{tabular}

13) For which of the following purposes is your performance appraisal scheme used?

Please tick the appropriate number alongside each method, and add any you use, but which are not listed, indicating the amount it is used.

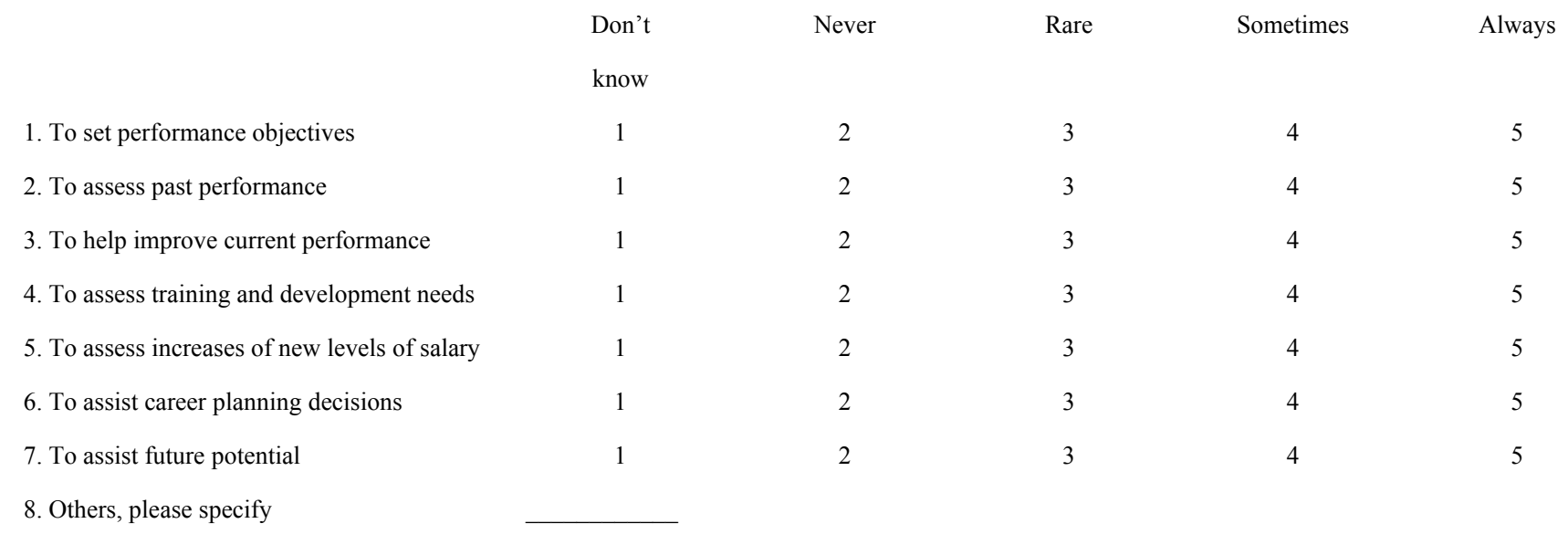

14) What is the number of years of your company in business?
1. $<2$
2. $2-5$
3. $>5-\leq 10$
4. $>10-\leq 15$
5. $>15$

15) What was your company's gross income for the last year (HK\$)?
1. 0
2. $\leq 5,000,000$
3. $>5,000,000-\leq 10,000,000$
4. $>10,000,000-\leq 50,000,000$
5. $>50,000,000$

16) What is the number of employee in your organisation?
$1 . \leq 5$
2. $>5-\leq 10$
3. $>10-\leq 50$
4. $>50-\leq 100$
5. $>100$ 
17) Are you satisfied with your income?
Very
Dissatisfied
Neither
Satisfied
Very

Unsatisfied

Satisfied

5

18) Are you satisfied with your personal success?

$\begin{array}{llll}\text { Very } & \text { Dissatisfied } & \text { Neither } & \text { Satisfied }\end{array}$

Unsatisfied

2

3

Satisfied

5

19) Are you satisfied with your progress made towards your overall career goals?

$\begin{array}{llll}\text { Very } & \text { Dissatisfied } & \text { Neither } & \text { Satisfied }\end{array}$

Unsatisfied

Satisfied

5

20) Are you satisfied with the economic development of your businesses?

Very

Unsatisfied

1
Dissatisfied
Neither

3
Satisfied

Very

Satisfied

4
5

Thank you

\section{REFERENCES}

[1]

Dessler G. Human Resource Management. New Jersey: Prentice Hall 2004.

[2] Estes RJ. Quality of life in Hong Kong: past accomplishments and future prospects. Soc Indic Res 2005; 71: 183-229.

[3] Chan RCK. Towards strategic planning and regional sustainability: Hong Kong in the Pearl river Delta region. Sustain Dev 2002; 10(3): 122-30.

[4] Hong Kong Government. CEPA. HKSAR, 2006, http://www.tid.gov.hk/english/cepa/index.html
[5] Yu FL. Hong Kong's entrepreneurship behaviours and determinants. Entrepreneur Region Dev 2000; 12: 179-94.

[6] Goh PY, Cheung PY. Report of Hong Kong human resource management practices survey. Hong Kong: Manage Dev Centre Hong Kong 1989.

[7] Krejcie R, Morgan D. Determining sample size for research activities. Educ Psychol Meas 1970; 30: 607-10.

[8] Dillman DA. Increasing mail questionnaire response in large samples of the general public. Public Opin Quart 1972; 36: 254-7.

(C) Fanny Yuk Fun Young; Licensee Bentham Open.

This is an open access article licensed under the terms of the Creative Commons Attribution Non-Commercial License (http://creativecommons.org/licenses/ by-nc/3.0/) which permits unrestricted, non-commercial use, distribution and reproduction in any medium, provided the work is properly cited. 